\title{
An Analysis of Airport Delays Across the United States, 2012-2018
}

\author{
Isaac Byrne ${ }^{\mathrm{a}}$, Yuichiro Kanaoka ${ }^{\mathrm{a}}$, Nicole E. Pollack ${ }^{\mathrm{a}}$, Ho June Rhee ${ }^{\mathrm{a}}$, Paul M. Sommers ${ }^{\mathrm{a}}$
}

The authors examine the two busiest airports (based on the annual number of flight departures) in each state (including the District of Columbia) in 2012, 2016, 2017, and 2018. The average delay is longest among states in the Northeast and shortest among states in the West in each of the four years. Between 2012 and 2016, the average delay increased in all four Census regions, but significantly in only the Midwest and West. The year-over-year change in the average delay between 2016 and 2018 did not significantly increase at the busiest airports in states in either the West or, surprisingly, the most densely populated Census region, the Northeast.

Keywords: airport delays, t-tests, simple regression

Flights delays are the bête noire of air travelers. Eyes cast on departure boards dread the sight of "DELAYED" almost as much as the word "CANCELLED". Timeliness, of course, depends on many factors including the weather, the airport, the airline, security issues, and the departure time - the earlier in the morning, the less likely the delay. In this short research note we analyze average flight delay per departure (hereafter, operation) at the nation's two busiest airports in each state (including the District of Columbia) in each of four different years - 2012, 2016, 2017, and 2018. One would expect that in the most densely populated parts of the country, notably in states in the Northeast, average flight delays would be the longest and that in all parts of the country, average flight delays have become progressively longer with each passing year.
The United States Census Bureau divides the nation into four regions - Northeast, Midwest, South, and West. The Northeast includes nine states: Maine, New Hampshire, Vermont, Massachusetts, Rhode Island, Connecticut, New York, New Jersey, and Pennsylvania. The Midwest includes twelve states: Ohio, Michigan, Wisconsin, Illinois, Indiana, Minnesota, Iowa, Missouri, North Dakota, South Dakota, Nebraska, and Kansas. The South includes sixteen states (more than any other region): Delaware, Maryland, Virginia, West Virginia, Kentucky, North Carolina, South Carolina, Tennessee, Georgia, Florida, Alabama, Mississippi, Arkansas, Louisiana, Texas, Oklahoma, and the District of Columbia. And, the West includes thirteen states: Montana, Idaho, Wyoming, Colorado, New Mexico, Arizona, Utah, Nevada, California, Oregon, Washington, Alaska, and Hawaii.

\section{The Data}

Figure 1. The Two Busiest Airports in Each State, 2012-2018

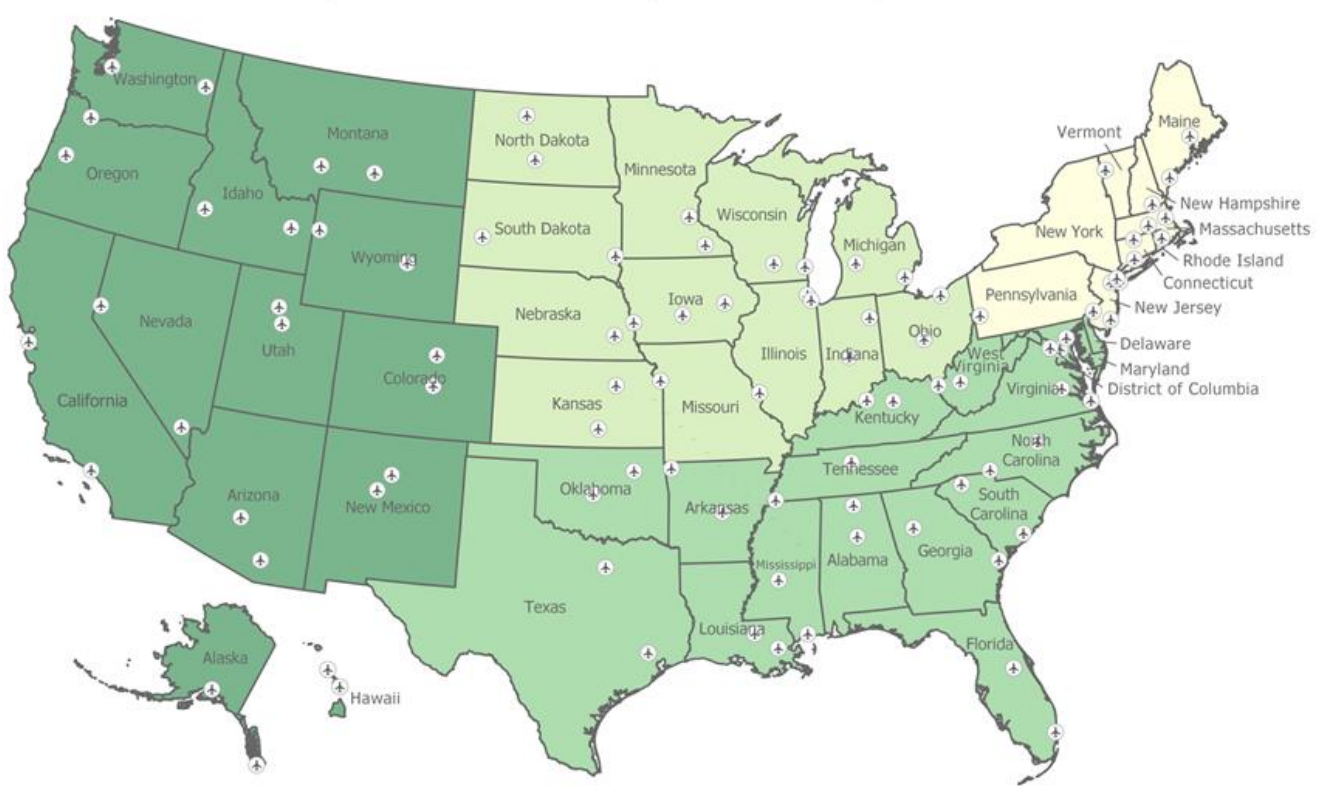

a. Department of Economics, Middlebury College, Middlebury, VT, 05753 
Research Article (2019)

For each state (including the District of Columbia), we identified the two busiest airports based on their number of annual operations (flight departures) in each of four years: 2012, 2016, 2017, and 2018. Figure 1 depicts a map of the U.S. showing the location of the airports in our study. We recorded the average delay (in minutes) per operation for each of the state's two busiest airports with a minimum of 500 operations in each of the four years. All data were obtained from the U.S. Department of Transportation [1]. ${ }^{1}$

\section{Methodology}

We conducted a series of paired $t$-tests on the average delay at airports within a Census region across years. Are average delays increasing or are they improving at the same airports within a given Census region over time?
We then conducted a series of two-sample $t$-tests on the average delay across Census regions in each of the four years. Do the same differences between regions persist over time?

Finally, we were curious to know what (if any) relationship exists between the average delay and the number of operations. For each region in each year (and for all four regions combined in each year), we regressed the average delay on the number of operations. If there is a direct relationship, then the slope coefficient would be positive and discernible from zero. That is, the larger the number of operations (the busier the airport), the longer the average delay per operation.

\section{The Results}

Table 1. Differences in Average Flight Delay Across Years by Census Region

\begin{tabular}{|c|c|c|c|c|}
\hline \multicolumn{2}{|c|}{ Years } & \multicolumn{2}{|c|}{ Average Delay (min) } & \multirow{2}{*}{$\begin{array}{l}p \text {-value on } \\
\text { difference a }\end{array}$} \\
\hline Group 1 & Group 2 & Group 1 & Group 2 & \\
\hline \multicolumn{5}{|c|}{ Northeast } \\
\hline $2012(\mathrm{n}=12)$ & $2016(\mathrm{n}=12)$ & 11.250 & 12.433 & 0.2772 \\
\hline $2012(\mathrm{n}=12)$ & $2017(\mathrm{n}=12)$ & 11.250 & 14.325 & 0.0377 \\
\hline $2012(\mathrm{n}=12)$ & $2018(\mathrm{n}=12)$ & 11.250 & 14.692 & 0.0061 \\
\hline $2016(n=14)$ & $2017(\mathrm{n}=14)$ & 12.636 & 14.157 & 0.2511 \\
\hline $2016(\mathrm{n}=14)$ & $2018(\mathrm{n}=14)$ & 12.636 & 15.214 & 0.0415 \\
\hline $2017(\mathrm{n}=14)$ & $2018(\mathrm{n}=14)$ & 14.157 & 15.214 & 0.4519 \\
\hline \multicolumn{5}{|c|}{ Midwest } \\
\hline $2012(\mathrm{n}=23)$ & $2016(n=23)$ & 8.926 & 9.909 & 0.0492 \\
\hline $2012(n=24)$ & $2017(n=24)$ & 8.904 & 11.642 & 0.0001 \\
\hline $2012(n=24)$ & $2018(\mathrm{n}=24)$ & 8.904 & 11.942 & $<.0001$ \\
\hline $2016(n=23)$ & $2017(\mathrm{n}=23)$ & 9.909 & 11.396 & 0.0147 \\
\hline $2016(n=23)$ & $2018(\mathrm{n}=23)$ & 9.909 & 11.909 & 0.0005 \\
\hline $2017(\mathrm{n}=24)$ & $2018(\mathrm{n}=24)$ & 11.642 & 11.942 & 0.6563 \\
\hline \multicolumn{5}{|c|}{ South } \\
\hline $2012(\mathrm{n}=30)$ & $2016(n=30)$ & 10.010 & 10.183 & 0.6405 \\
\hline $2012(\mathrm{n}=30)$ & $2017(\mathrm{n}=30)$ & 10.010 & 10.867 & 0.0543 \\
\hline $2012(\mathrm{n}=30)$ & $2018(\mathrm{n}=30)$ & 10.010 & 12.107 & $<.0001$ \\
\hline $2016(\mathrm{n}=30)$ & $2017(\mathrm{n}=30)$ & 10.183 & 10.867 & 0.1307 \\
\hline $2016(n=30)$ & $2018(\mathrm{n}=30)$ & 10.183 & 12.107 & $<.0001$ \\
\hline $2017(\mathrm{n}=30)$ & $2018(\mathrm{n}=30)$ & 10.867 & 12.107 & 0.0050 \\
\hline \multicolumn{5}{|c|}{ West } \\
\hline $2012(\mathrm{n}=25)$ & $2016(\mathrm{n}=25)$ & 7.616 & 9.324 & 0.0446 \\
\hline $2012(\mathrm{n}=25)$ & $2017(\mathrm{n}=25)$ & 7.616 & 9.964 & 0.0074 \\
\hline $2012(\mathrm{n}=25)$ & $2018(\mathrm{n}=25)$ & 7.616 & 10.000 & 0.0064 \\
\hline $2016(\mathrm{n}=25)$ & $2017(\mathrm{n}=25)$ & 9.324 & 9.964 & 0.4705 \\
\hline $2016(\mathrm{n}=25)$ & $2018(\mathrm{n}=25)$ & 9.324 & 10.000 & 0.4443 \\
\hline $2017(\mathrm{n}=25)$ & $2018(\mathrm{n}=25)$ & 9.964 & 10.000 & 0.9678 \\
\hline
\end{tabular}

${ }^{a}$ All $p$-values in boldface are significant at better than the .05 level for a two-tailed test. 
Table 1 summarizes the results of twenty-four paired $t$-tests, six year-to-year comparisons for each of the four Census regions. All fourteen significant results (using $\alpha=.05$ ) show a longer average delay relative to the average delay in a previous year. For all four Census regions, there was a significantly longer average delay in 2018 than in 2012. For three of the four regions (the South notwithstanding), there was a longer average delay in 2017 than in 2012. For two of the four regions (the Northeast and South notwithstanding), there was a longer average delay in 2016 than in 2012. For three of the four regions (the West notwithstanding), there was a longer average delay in 2018 than there was two years earlier. In 2018, airports in only the South experienced significantly longer average delays than in the previous year. For airports in the West and the Northeast, average delays did not change from one year to the next over the last three years. They are higher one year to the next, but not discernibly higher. Air travelers in Western states experienced the biggest jump in average delays between 2012 and 2016. But, since 2016, clearly the West is best.

Table 2. Differences in Average Flight Delay Across Census Regions by Year

\begin{tabular}{|c|c|c|c|c|}
\hline \multicolumn{2}{|c|}{ Census Region } & \multicolumn{2}{|c|}{ Average Delay (min) } & \multirow{2}{*}{$\begin{array}{l}p \text {-value on } \\
\text { difference }\end{array}$} \\
\hline Group 1 & Group 2 & Group 1 & Group 2 & \\
\hline \multicolumn{5}{|c|}{2012} \\
\hline Northeast $(n=12)$ & Midwest $(\mathrm{n}=24)$ & 11.250 & 8.904 & 0.0019 \\
\hline Northeast $(\mathrm{n}=12)$ & South $(\mathrm{n}=30)$ & 11.250 & 10.010 & 0.0406 \\
\hline Northeast $(\mathrm{n}=12)$ & West $(n=25)$ & 11.250 & 7.616 & 0.0004 \\
\hline Midwest (n=24) & South $(\mathrm{n}=30)$ & 8.904 & 10.010 & 0.0119 \\
\hline Midwest (n=24) & West $(n=25)$ & 8.904 & 7.616 & 0.0587 \\
\hline South $(\mathrm{n}=30)$ & West $(n=25)$ & 10.010 & 7.616 & 0.0001 \\
\hline \multicolumn{5}{|c|}{2016} \\
\hline Northeast $(\mathrm{n}=14)$ & Midwest $(n=23)$ & 12.636 & 9.909 & 0.0006 \\
\hline Northeast $(n=14)$ & South $(\mathrm{n}=30)$ & 12.636 & 10.183 & 0.0006 \\
\hline Northeast $(\mathrm{n}=14)$ & West $(n=25)$ & 12.636 & 9.324 & 0.0022 \\
\hline Midwest (n=23) & South $(n=30)$ & 9.909 & 10.183 & 0.5095 \\
\hline Midwest $(n=23)$ & West $(n=25)$ & 9.909 & 9.324 & 0.4138 \\
\hline South $(\mathrm{n}=30)$ & West $(n=25)$ & 10.183 & 9.324 & 0.1803 \\
\hline \multicolumn{5}{|c|}{2017} \\
\hline Northeast $(\mathrm{n}=14)$ & Midwest $(n=24)$ & 14.157 & 11.642 & 0.0221 \\
\hline Northeast $(n=14)$ & South $(n=30)$ & 14.157 & 10.867 & 0.0005 \\
\hline Northeast $(\mathrm{n}=14)$ & West $(n=25)$ & 14.157 & 9.964 & 0.0008 \\
\hline Midwest $(n=24)$ & South $(n=30)$ & 11.642 & 10.867 & 0.2165 \\
\hline Midwest $(n=24)$ & West $(n=25)$ & 11.642 & 9.964 & 0.0484 \\
\hline South $(\mathrm{n}=30)$ & West $(n=25)$ & 10.867 & 9.964 & 0.1988 \\
\hline \multicolumn{5}{|c|}{2018} \\
\hline Northeast $(\mathrm{n}=15)$ & Midwest $(n=24)$ & 15.173 & 11.942 & 0.0005 \\
\hline Northeast $(\mathrm{n}=15)$ & South $(\mathrm{n}=31)$ & 15.173 & 12.187 & 0.0001 \\
\hline Northeast $(\mathrm{n}=15)$ & West $(n=26)$ & 15.173 & 10.012 & $<.0001$ \\
\hline Midwest $(n=24)$ & South $(n=31)$ & 11.942 & 12.187 & 0.5874 \\
\hline Midwest $(n=24)$ & West $(n=26)$ & 11.942 & 10.012 & 0.0118 \\
\hline South $(n=31)$ & West $(n=26)$ & 12.187 & 10.012 & 0.0007 \\
\hline
\end{tabular}

${ }^{a}$ All $p$-values in boldface are significant at better than the .05 level for a two-tailed test. 
Table 2 summarizes the results of twenty-four two-sample $t$-tests, six region-by-region comparisons for each of the four years. The most notable result in this table is the significantly longer flight delays in the Northeast relative to all other regions in all four years. Another notable result is the relatively short average delay in the West relative to not only the Northeast, but also relative to the Midwest (in 2017 and 2018) and the South (in 2012 and 2018).

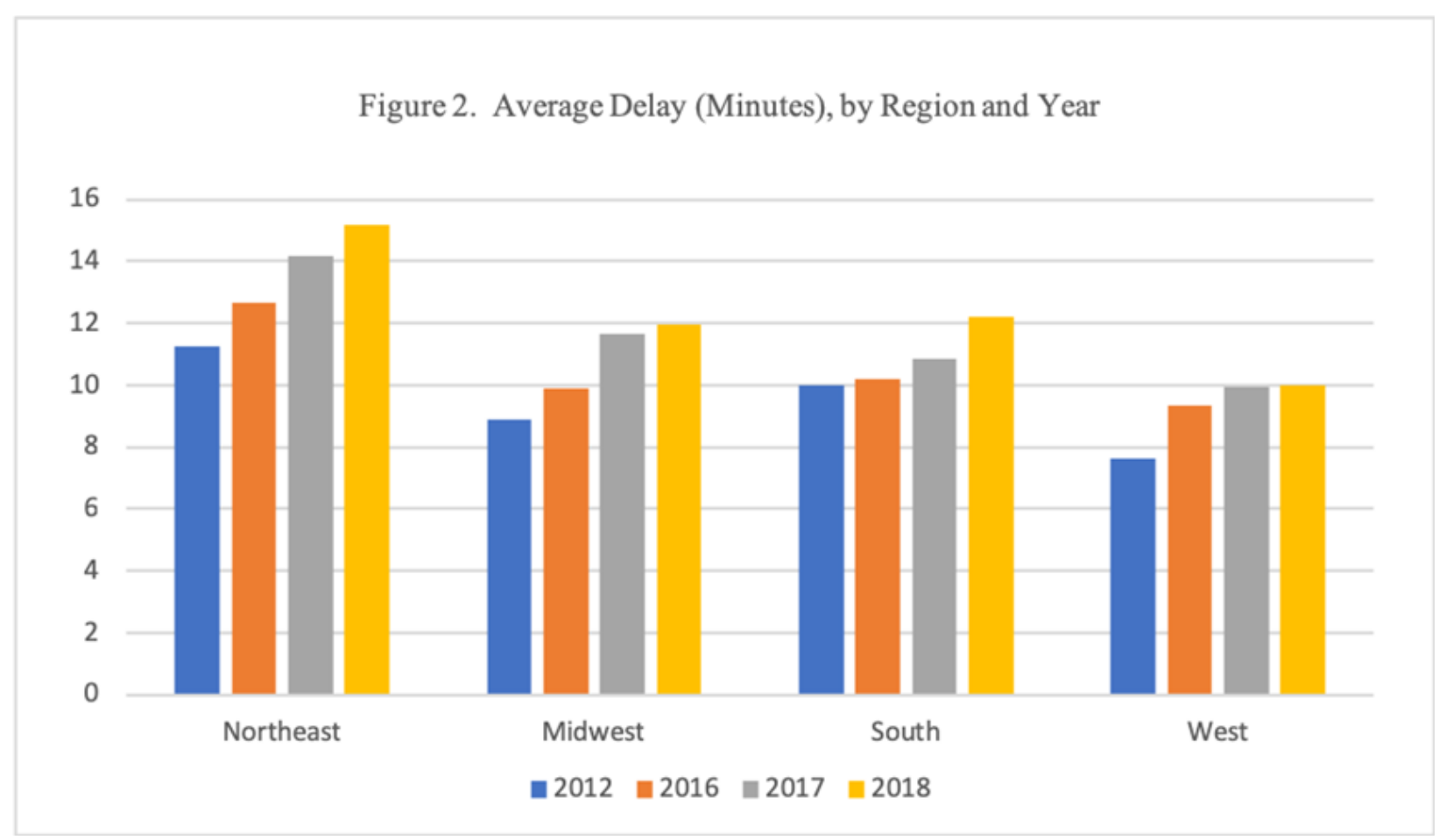

Figure 2 shows the average delay (minutes) by region across the four years. The bar graph clearly shows the longest average delays in the Northeast and the shortest average delays in the West, all four years. Over the last three years (from 2016 to 2017 and from 2017 to 2018), there has been practically no change in average airport delays in either the Northeast or the West.

Finally, our regression results for the nation's busiest airports show almost no evidence of a direct relationship between average delay and the total number of operations. For all regions combined, there was no relationship in any of the four years (again using $\alpha=.05$ ). For each region in each of the four years (sixteen total regressions), we obtained only two significant results: an inverse relationship between average delay and operations at airports in the South $(2012, p$-value on the slope coefficient was .037) and a direct relationship between average delay and operations at airports in the Northeast $(2017, p=.002)$.

\section{Concluding Remarks}

An analysis of average flight delays at each state's two busiest airports over the last three years (2016, 2017, and 2018) relative to 2012 shows longer average delays, especially in the Northeast, but surprisingly little change in the West. Based on these data, there is no evidence that longer average flight delays are anything more than a reflection of the increasing number of flight departures in each region. The combined number of operations at a state's two busiest airports across all states in each region was highest in 2018 compared to earlier years. Yet, airports in the West appeared to have done the best job of keeping flight delays in check. And, surprisingly, although flight delays were longest in the Northeast, the change from one year to the next since 2016 was not statistically discernible.

\section{Acknowledgment}

The authors wish to thank Bill Hegman, GIS Specialist/Teaching Fellow, at Middlebury College for his assistance in creating the map in Figure 1.

\section{Reference}

1. Annual (2012, 2016, 2017, and 2018) airline traffic data are from the U.S. Bureau of Transportation Statistics. Retrieved June 23, 2019 from https://www.bts.dot.gov/.

\section{Footnote}

1. Missing data on a state's two busiest airports included one airport each in New Jersey and Massachusetts (2012); Kansas (2016); Connecticut, West Virginia, and Utah (2012, 2016, 2017); and New Hampshire, Rhode Island, Vermont, and Maryland (2012, 2016, 2017, 2018). 